\title{
Accreditation of Study Programs in Business and Information Systems Engineering: Towards more Competitiveness or Towards more Bureaucracy?
}

DOI 10.1007/s12599-009-0064-1

\author{
The Authors \\ Prof. Dr. Robert Winter \\ Universität St. Gallen \\ Institut für Wirtschaftsinformatik \\ Müller-Friedberg-Strasse 8 \\ 9000 St. Gallen \\ Switzerland \\ robert.winter@unisg.ch \\ Prof. Dr. Elmar J. Sinz, \\ Prof. Dr. Thomas Dyllick, \\ Prof. Dr. Karl Kurbel, \\ Dr. Heinz-Ulrich Schmidt, \\ Prof. Dr. Torsten Eymann
}

This article is also available in German in print and via http://www.wirtschaftsinformatik.de: Winter R (2009) Akkreditierung von Wirtschaftsinformatik-Studiengängen: Stärkung der Wettbewerbsfähigkeit oder Stärkung der Bürokratie? WIRTSCHAFTSINFORMATIK. doi: 10.1007/11576-009-01795.

Accreditation means that a supplier's statements on process and product quality are confirmed for (prospective) customers by an independent authority. The fewer different types of accreditation exist the more likely it is that the (prospective) customers ascribe them unifying, comparabilitygenerating and/or selection-supportive effects.

Accreditation only makes sense and becomes possible if offers are comparable. From the perspective of university study program providers it can be useful to differ from other offers by specific content, formats, and processes. In contrast, companies as the indirect consumers of education and subsequently also the immediate "customers" of education (i. e. students and prospective students) have a great interest in standardized qualifications. Comparable qualifications provide companies with a larger selection of candidates, open up a greater choice of companies for applicants, and generally allow a targeted selection of study offers.

Traditionally, formats and process quality have been highly standardized for university-level education in the Germanspeaking countries by means of government regulation (e. g. in the form of professor qualification, academic organization and supervision). Moreover, basic recommendations also promoted the standardization of content in the specific fields. For studies at universities and universities of applied science, these were e. g. developed by the Scientific Commission for Business and Information Systems Engineering (BISE) of the German Academic Association for Business Research. In such a situation accreditation has little value.

On the one hand, the Bologna process is leading to an EU-wide standardization of teaching and studying formats and degrees. On the other hand, however, the range of process quality and content is not only growing considerably due to the different traditions and regulations of the participating countries; in addition, new providers such as private and commercial institutions or organizations located outside of the EU are entering the market. Since the density of regulation in all EU countries tends to decrease and no EUwide recommendations regarding content are evolving, there is growing demand for comparable, independent statements on the product and process quality in higher education - in BISE as in other disciplines.

Since accreditation is relatively new at least in German-speaking countries, there are different approaches with regard to the subject of accreditation (study program, faculty, the overall institution), focus of accreditation (processes, "products", resources), and process of accreditation (e. g. management on part of the education provider), etc. Accreditation is conducted by institutions operating nationwide, across Europe as well as worldwide, which, additionally, are more or less aligned to the specific subject. The perception of accreditations by the participating target groups, which are the indirect education customers (companies), direct education customers (students and prospective students), university management, accreditation organizations, deployed experts, and last but not least researchers and teachers, is very diverse.

This discussion therefore deals with the question of whether accreditation of BISE study programs strengthens competitiveness or bureaucracy. As the perception of university teachers, university management, reviewers, and accreditation institutions may differ significantly, we invited contributions from representatives of these different perspectives. Apart from a general description of their experience, the contributors were asked to comment on the following questions, if possible:

- Are there any side effects of accreditation (and if so, which) on the freedom of teaching and research?

- Are there any side effects of accreditation (and if so, which) on the relationship between lecturers/ researchers and the university management?

- Is accreditation about quality assurance of processes, of services/ products or both?

- What are the costs and what are the benefits of accreditation? Are there any differences between the accreditation institutions in this regard?

- How deeply is accreditation/ are accreditation agencies embedded in certain cultures and what are the consequences?

- Are new roles emerging through accreditation and re-accreditation (quality manager, program manager/ 
product manager) and how are they positioned (and filled) at universities?

- How strong is the signal effect of accreditations? Are there any differences in effect between different target groups and/ or between accreditation institutions?

- How can the "right" accreditation be selected?

My invitation to this discussion was accepted by (in alphabetical order):

- Prof. Dr. Thomas Dyllick, who has been vice-president of the University of St. Gallen (HSG) for teaching and this role he is responsible for internal quality assurance and development as well as for all accreditations. He is also a member of the EQUIS Committee, which decides on the admission of candidates to the EQUIS accreditation and actively works as a member and director of international peer review teams for the EQUIS accreditation himself. As vice-president of the University of St. Gallen, he was and still is responsible for the initial and re-accreditation of the HSG with EQUIS as well as the HSG's School of Management with AACSB.

- Prof. Dr. Torsten Eymann, University of Bayreuth, was/ is a peer reviewer in BISE accreditation processes.

- Prof. Dr. Karl Kurbel, Europe University Viadrina Frankfurt/Oder, has been accredited as dean of the international study program Master of Business Informatics.

- Dr. Heinz-Ulrich Schmidt, managing director at the FIBAA, is responsible for a large accreditation institution.

- Prof. Dr. Elmar J. Sinz deals with BISE accreditations as dean of the BISE department at the University of Bamberg. Moreover he has acted as chairman of the technical committee for BISE at the accreditation agency ASIIN from 2000-2008 and as a member of the committee for computer science at ACQUIN since 2002.

Prof. Sinz gives an overview of the process and the different types of accreditation. He conducts a classification of accreditation types in higher education and sums up his experience to recommendations for effective accreditations.

Prof. Dyllick focuses on the importance of quality management in general, which can be developed in the course of accreditation. In particular, he points to the chalquality development since 2002. In

lenge of integrating quality management as part of the overall university organization and designing the resulting tension between academia and administration in a balanced way.

Prof. Kurbel reports on the volume of work entailed by accreditation from the perspectives of an accredited study program. In particular, he emphasizes the dangers of an unreflected accreditation restraint which massively binds resources without creating differentiation opportunities.

From the perspective of the FIBAA, Dr. Schmidt makes clear that accreditation mainly has a positive effect on the decision of the students for a particular course of study. Moreover, he identifies improvement potentials for cooperation between universities and accreditation agencies.

Finally, Prof. Eymann particularly points to the positive effect of the preparation of the final accreditation and emphasizes the importance of actual "peers" as a quality criterion for accreditation procedures.

The contributions show that the accreditation of study programs not only has external effects, but also leads to reflection within the universities. In the ideal case, the external effect results in a higher attractiveness of a study program, whereas internally an effective and permanently anchored quality management is promoted - primarily for teaching, but also indirectly for scientific research. At the same time, the contributions make clear that accreditation is connected to relatively high expenses so that compulsory accreditation without an active quality management does not appear useful.

If you would like to comment on this topic or another article of the journal Business \& Information Systems Engineering (BISE), please send your contribution (max. 2 pages) to Hans-Ulrich.Buhl@ wiwi.uni-augsburg.de.

Prof. Dr. Robert Winter Institute of Information Management University of St. Gallen

\section{Bologna process and accreditation}

The goal of the "Bologna Process" initiated in 1999 is the creation of a common European Higher Education Area (EHEA) by 2010. The core element of EHEA is to introduce a graded system of bachelor's and master's degrees, which should be comparable across Europe. In order to face the increased demands on international competitiveness of the new study programs, accreditation has also been introduced in Germany in order to provide a measure for quality assurance of study programs and has been integrated in various forms into the university and college acts of the federal states. For example, according to the university and college act of North Rhine-Westphalia, introducing a study program requires the successful completion of the accreditation, while the Bavarian university and college act stipulates that the accreditation is to be accomplished by means of quality assurance (see also Sinz 2008).

The aim of the accreditation is to ensure minimum requirements for study programs. Evaluation criteria particularly consist of the university's quality concept with regard to teaching, the qualification objectives of the study program, the conceptual classification of the program, the course concept, the implementation of the program, the examination system, transparency and documentation as well as quality assurance.

The German system of accreditation (Akkreditierungsrat 2009a) is organized in a decentralized manner. The accreditation of study programs is carried out by competing accreditation agencies. On their part, these agencies are accredited by the accreditation council (German: Akkreditierungsrat). Currently, there are seven accreditation agencies which are entitled to award the quality seal of the accreditation council. Accreditation is limited to a maximum period of five years. After this period, a re-accreditation becomes necessary.

In addition to the accreditation of individual study programs (program accreditation), currently the accreditation of 
internal quality assurance systems at universities (system accreditation) is being tested. In the course of system accreditation, all study programs of a university which have gone through this quality assurance system are accredited for a period of six years.

\section{State of accreditation and current discussion on higher education policies}

Currently (April 2009), the database of the accreditation council reports more than 4,500 accredited study programs (Akkreditierungsrat 2009b). Slightly more than 100 accounts are allotted to the field of BISE. Several study programs are already in the process of re-accreditation.

While the number of accredited study programs is constantly increasing, there is massive criticism concerning the accreditation system. For example, the German Association of University Professors and Lecturers (Deutscher Hochschulverband 2009) will "if necessary enforce its demands for a fundamental redesign of the accreditation system in Germany by calling on its 24,000 members not to volunteer for reviewing program accreditations in future." In its annual report from 2008, the Thuringian Audit Court determines that "the procedures were 'bloated bureaucratically' and due to the agencies' latitude of judgment 'neither led to unified nor reliable assessment results"“ (n. a. 2009, p. 5).

\section{Costs and benefits of program accreditation}

The cost for accreditation is considerable from the universities' as well as from the agencies' perspective. The study programs' self-documentation for forthcoming accreditation including all statutes and study documents as well as the module handbook in particular, which is to be created by the universities, generally comprises several hundred pages. The agency must form a group of reviewers who read and assess these documents. The inspection at the university has to be prepared and carried out. The final report has to be compiled; the technical committee and accreditation commission have to be involved. At the end of 2007, the accreditation agency ASIIN reported the accreditation of more than 1,200 study programs with the participation of 1,300 experts and 200 other volunteers in the committees (Wasser 2007, p. 1).

What benefits recompense these costs? In many cases, the main benefit may already be generated in the preparatory phase of accreditation, which is during the development of the self-documentation. The accreditation enforces all relevant documents to be presented in a consistent, complete, and up-to-date form. This supports decision making among the school members as well as overcoming certain animosities between departments. Reflection processes for the coordination of objectives and contents of study programs will be initiated (renewed and deepened). Also the university management has to commit itself clearly to the strategic positioning of forthcoming programs for accreditation. Imbalances in the resources equipment of courses can be discovered and can later be removed more easily in the process of voting for the accreditation. The external effect of accreditation with regard to the reputation of study programs we can also count towards the benefits.

The question arises whether the described benefits are worth the effort. After all, accreditation is "merely" based on the principle of compliance with minimum standards. In analogy to vehicle safety inspections, accreditation is intended to prevent study programs with substantial deficiencies regarding content and quality on the education market. In response we can state that the minimum standards set are consistently very high. Moreover, most accreditation procedures go beyond the principle of minimum standards and provide constructive recommendations for further developing study programs. Against the background of increasing international networking of accreditation systems, this view from the outside may provide valuable suggestions for strengthening competitiveness.

\section{Requirements for the implementation of accreditation procedures}

While in previous years the approval for the establishment of study programs and related examinations lay in the responsibility of the ministries of science of the federal states, today these merely at best decide on the establishment permit. Questions of content and formal structure of study programs are outsourced to the accreditation process. Therefore, it is gen- erally impossible to avoid accreditation. It is here that the decision is taken whether a study program meets the necessary quality standards and whether its content structure corresponds to the ideas of faculty culture. If a study program does not reach this, further obligations or in the worst case the denial of accreditation impend.

Thus, the accreditation process provides a significant instrument of power. Especially interdisciplinary or innovative study programs, which may appear strange at first glance, can be caught in the crossfire of the traditional faculty cultures.

All the more important it is for agencies to make a real effort to prove professionalism and a high degree of self-discipline during the implementation of accreditation procedures. Some examples will illustrate this fact:

- Holding a mirror up: The review groups should be guided by the metaphor of holding up a mirror to the applying university to discover weaknesses and offer help for self-help. Ideological positions in reviewing groups and technical committees, know-it-all attitudes, and pettiness (e. g. in the case of requirements for the module manual's design) should be avoided.

- Showing trust: Distrust is a bad advisor. We may usually assume that the applying institution is honestly attempting to offer competitive study programs. This point particularly becomes relevant in the context of notifiable substantial changes of accredited study programs as well as in the case of re-accreditation. Here we have to face the danger of the accreditation system developing into a permanent bureaucratic control institution and thus rather preventing than promoting the further development of study programs. Unlike vehicle inspections, this is not about approval termination in the case of unauthorized changes to a vehicle.

- Paying attention to sufficient expertise: Especially in the case of interdisciplinary subjects such as BISE, it is essential to be adequately represented in the accreditation agencies' technical committees, and not only to be represented by the technical committees of 'reference' disciplines.

- There will be increasingly more accreditation procedures dealing not only with a single study program, but a more or less heterogeneous bundle of 
related programs (cluster method). In this case it is important to ensure that the reviewers have sufficient expertise. If a study program of the cluster is only represented by a single reviewer or only by a reviewer from a related discipline, a balanced assessment cannot be ensured.

Beyond individual accreditation procedures technical committees should particularly be sensitive regarding possible external influences on the policy of the accreditation agencies. While in the ideal case the accreditation system perceives itself as an institution for self-help by universities for universities, it cannot be excluded that, for example, professional associations use their membership in an accreditation agency's body to pursue particular interests, which in extreme cases may affect university autonomy. Another source of potential influence can be seen in the accreditation agencies themselves. Since the various accreditation agencies are in competition, their "business models" are not only geared towards the quality competition, but also towards sales, market share, and survival.

\section{Conclusion}

The accreditation process should ideally result in creating trust on the part of potential students, university management, and the responsible ministry of science, that the accredited study program's objectives and content are aligned and that both content and quality meet international standards. In addition, the university should receive valuable suggestions concerning the design and development of its range of courses.

The current discussion on university policies suggests that this objective is not always reached, and thus the benefits achieved only partially justify the costs. As a resort, system accreditation is being tested. Here the internal quality management of the university is on trial, only accompanied by a sample of program accreditations. The question arises how far universities and the accreditation system are prepared for the associated requirements.

Prof. Dr. Elmar J. Sinz Chair of Information Systems, especially Systems Engineering University of Bamberg

\section{References}

Akkreditierungsrat (2009a). http://www.akkreditierungsrat.de/index.php?id=22. Accessed 2009-04-26

Akkreditierungsrat (2009b). http://www. hochschulkompass.de/kompass/xml/akkr/ maske.html. Accessed 2009-04-26

Deutscher Hochschulverband (2009). http:// www.hochschulverband.de/cms1/ pressemitteilung+M53b7fb95070.html. Accessed 2009-04-26

na (2009) Rechnungshof: „Akkreditierung nicht weiter hinnehmbar und praktizierbar". Forschung \& Lehre. 2009(1):5

Sinz EJ (2008) Akkreditierung. In: Kurbel K, Becker J, Gronau N, Sinz EJ, Suhl L (eds) Enzyklopädie der Wirtschaftsinformatik - Online-Lexikon, $2^{\text {nd }}$ edn. Oldenbourg, Munich. http://www.enzyklopaedie-der-wirtschaftsinformatik.de. Accessed 2009-04-26

Wasser I (2007) ASIIN Newsletter. 2007 (1). http:// www.asiin.de/deutsch/download/ASIINNewsletter_01_Dezember_2007.pdf. Accessed 2009-04-26

\section{Confessions of a University Quality Manager: The Example of the University of St. Gallen}

The University of St. Gallen (HSG) volunteered for accreditation by EQUIS ${ }^{1}$ in 2001 and by $\mathrm{AACSB}^{2}$ in 2003, awarding it the right to use these prestigious international seals of quality. Meanwhile, it has been reaccredited by both organizations. In 2004, it also had to undergo a quality audit at national level by the Swiss institution of accreditation and quality assurance (OAQ) in order to be able to further receive federal funds. Recently, this quality audit has been repeated as well. Whereas the first two institutions are specific institutional accreditations for business schools, the latter constitutes a general procedure for auditing the university quality management system (QMS).

The beginning of the St. Gallen accreditation history went back to a more (regarding the commitment) or less (regarding the consequences) conscious decision to undergo an EQUIS accreditation, which fortunately led to the - initially only conditional - awarding of this desired label. This was a good start and ensured the motivation for the time being to gradually address the clearly identified weak-

\footnotetext{
European Quality Improvement System: http://www.efmd.org/accreditation/equis 2 Association to Advance Collegiate Schools of Business: http://www.aacsb. edu/accreditation/standards
}

nesses. The confrontation with the AngloSaxon world, which is significantly more developed with regard to quality assurance (QA) and development (QD), not only showed the political and cultural differences, but also revealed clearly visible deficits. In many cases, quality in research, teaching, and services tended to be more the result of successful individual efforts than the result of systematically controlled and jointly developed processes. It soon became clear that without an effective internal quality management these deficits could not be overcome, not to mention the safeguarding of keeping pace with the evolving requirements in the international area. As so often, the idea was to take a central function without compromising the locally existing skills and motivation. And that is certainly easier said than done.

Structural solutions not only have to be appropriate to the task, but also have to correspond to the specific organizational culture. Therefore, generalizations are difficult. This task called for a mix of central services and coordination and decentralized responsibility, but also for a mix of academic and administrative expertise. In this case, the leadership responsibility was laid in the hands of a vice-president, whose work focuses on the issues of internal QA/QD, accreditations, and rankings. ${ }^{3} \mathrm{~A}$ minor "position for QD“, which formally belongs to the administration, as well as a "Center for Research on Higher Education", which formally is incorporated into the Institute for Business Education, are assigned to his position. If necessary, temporary commissions or working groups come into operation. Due to the importance of the task and the difficulty of its implementation and further development, this is a typical management tasks at university level which cannot simply be delegated to university management. If this is done nevertheless, one should not be surprised if its implementation is carried out in a "bureaucratic" manner. What else could you expect?

The longer it takes, the more this task proves to be a complex management task with a variety of external and internal challenges. QA and QD are issues which are discussed and negotiated today in various national and international committees and forums. It is not just a ques-

\footnotetext{
This would be the right place to point to the unavoidable subjectivity of the present statements.
} 
tion of keeping up to date, but it is also about participating in the design of further developments. The findings are to be included in internal decision making processes at the universities and to be coordinated with other developments. The priorities of quality management (e. g. development of learning result orientation at program level) then have to be planned strategically and implemented operationally. The ongoing evaluation and development activities (e.g. course evaluations, graduates and alumni surveys, training and consulting services for research on higher education) have to be monitored and followed up by the responsible units, where regular information feedback and exchange with the local players is of high importance. In addition, there is a variety of specific events such as internal peer reviews of administrative units, supervision of accreditation procedures, supervision of ranking procedures in initial training, continuing education and research, internal communications and external reporting.

Given that this case is a highly externally-driven issue with politics, national committees, and international developments set the pace, the specialized positions will receive an important cross-border and mediating role. They observe the technical and political developments, represent the university in national and international committees as well as towards the accreditation organizations. By doing so, they inevitably not only act as internal spokesmen, but are also perceived as drivers of these developments. In contrast, the professors and academic committees may see themselves as "driven" by a not always fully understood or particularly valued development. Moreover, there is the reinforcing fact that professors who are not involved directly usually remain in distance to this issue, of which they do not desire to know so much. The fact that this may increase the feeling of being driven should not surprise.

Nevertheless, for the effectiveness and success of quality management it is crucial that we succeed in stimulating the local stakeholders involved (program directors, lecturers, students, administrative offices) and supporting them to implement and further develop QA and QD in their fields as autonomously as possible. ${ }^{4}$ Guidelines, action-related informa-

\footnotetext{
Cf. the guidelines of quality development at
}

tion, support services, but especially regular and personal communication serve this purpose. In other words it is a matter of quality-oriented cultural development activities. Thus, the program directors are systematically provided with program-specific and -comparative information in order to conduct QA and QD. The student body has begun to use student evaluation teams who systematically evaluate semester programs in coordination with the QD body and present their very constructive - results to the attending professors and administrative offices at the end of the semester. In addition, the students annually reward the best lecturer of the past year with a teaching award.

The challenge of a university quality management can be described as follows: quality management has to be perceived as a management task of the university to become effective. However, if it remains a responsibility of management alone, it will not be effective on the long run.

Against the background of the described experiences, I finally should shortly address the questions raised by the editors. Here, the answers are marked by the basic attitude that quality management at universities is generally seen as a useful task though we experience it to undoubtedly be a challenging task full of pitfalls:

- It is not apparent how the systematic method, transparency, and conscious reflection on one's own actions, which has resulted from the deployment of quality management, might lead to undesirable side effects for the freedom of teaching and research if the target of improvement is lost out of sight.

- Whether side effects on the relation between teachers/researchers and university management occur, crucially depends on how quality management is implemented and whether the academia or the administratia controls the process. However, we are not immune against the pitfalls of bureaucracy. This deliberately has to be checked periodically.

- In a world of limited resources and opportunities, fields of activities always have to be defined with priority and posteriority. Corresponding specifications should keep both in mind: the quality of services and the quality of the processes they are created by.

the University of St. Gallen: http://www.qualitaet. unisg.ch/Qualität als Aufgabe /Leitlinien.
- International accreditations enable comparisons with peer institutions. They provide important external incentives and templates for the further development of internal processes and services. Their strategic value cannot be measured using cost-benefit calculi.

- There are large differences between the accreditations according to EQUIS and AACSB and the national quality system audits. On the one hand, they result from very different standard requirements. On the other hand, they are influenced even more by the professional background of the external auditors. According to our experience it plays an important role whether they are peers bearing a leadership responsibility in comparable business schools themselves or representatives of accreditation organizations.

- Yes, new tasks and roles emerge (quality manager, program manager, research on higher education), when quality management is taken seriously. Here, a mixture of academic and administrative expertise is promising, while it is important that the academia controls the process.

- A signal effect of international accreditation only occurs as long as it has still not become a de facto requirement. Then it will be simply included. In the case of mandatorily introduced national accreditations we cannot talk of a signal effect.

\section{Prof. Dr. Thomas Dyllick Vice-president University of St. Gallen}

\section{Accreditation: More Bureaucracy, Less Flexibility, and Innovation-impeding}

When in 2000 I wanted to implement a new study program together with some colleagues, we first got to know the catchword accreditation. According to rumors, in future all courses should become "accredited". Nobody knew exactly what that meant; probably least of all the Ministry of Science, Research and Culture, whose understanding culminated in the claim: "New study programs will be approved only if they previously have been accredited." The accreditation agency, which we turned to, was surprised 
(„How should we assess a study program which does not yet exist?"), but probably did not want to miss out on this business and subsequently helped in a constructive way to interpret the situation.

Today, we know what the catchword means: a proliferation of bureaucracy and a rigid corset for education. Meanwhile, I am four-times accreditation-impaired, twice as chief worker, twice as supplier to the chief worker. Since all four procedures were successful, there probably must be a benefit - but at what cost? In the first procedure my personal effort amounted to three months of working time and the return was about 300 pages of paper partly written by myself and partly consolidated from inputs of 16 other professors.

One might argue that writing is a typical professor's task and therefore this is nothing special. However, what kind of BISE professor has the answers to a question like: "How far is the curriculum aligned to the application of scientific findings, theories, and models in the implementation of scientific-analytical methods and with regard to social skills?" At least, it enhanced creativity to generate such responses - as it seemed to become the case in the course of time for completion of questionnaires in general to, regardless of the matter, only generate accreditationproof answers.

If we include the effort of the 16 people doing the preliminary work (course-specific questionnaires, module handbooks, personal research/teaching qualification, etc.) and of the participants of the accreditation meeting with the reviewers, then the total time spent on the part of the professors begging for accreditation amounts to approximately 6 months for a person. This corresponds to about 50,000 Euros, applying a personnel cost rate for professors such as is used by the DFG. In addition, there are nearly 15,000 Euros to be paid to the agency. This does not include the effort on the part of the four accreditation reviewers, whose work was not rewarded (3 days of "inspection" at the university, arrival/departure and several days of preparation and revision).

There was no assistance in the development of accreditation documentation from the part of the university. Admittedly, a new colleague was employed based on project funds parallel to the accreditation process. However, she had to be familiarized with the issue, then became preg- nant and could not be replaced because of the tight financial situation of the university. Full-time positions for accreditation assistants still do not exist.

The second accreditation procedure took place at another agency and was more cost-effective with approximately $60 \%$ of the above mentioned effort. In the third and fourth round, which mainly have been carried out by other colleagues, the effort may have returned to something near to my initial experience.

No matter whether the costs of accreditation in each case were higher or lower than 65,000 Euros: they refer only to a single study program. A smaller university has dozens of programs, a large one has hundreds of them. Due to a lack of availability of accountable data, we shall refrain from an extrapolation to the whole economy, but three-digit million amounts are uselessly wasted. Let's not even try to imagine the quality of teaching or research which would have been achieved if this amount had been spent for tutoring programs or main research!

What benefit does recompense this cost? At first sight, the benefit consisted in satisfying the ministry resulting in approved study programs in the cases mentioned above. In no case did accreditation lead to a quality change - unless we consider written answers to form questions which the lecturers cannot identify with as improved quality. Responsible lecturers still design their courses in the way that students receive the best possible education, and less quality-conscious lecturers do not.

Moreover, the physical equipment of the courses has not changed due to accreditation, according to my observation. An accreditation seal does not improve the students' education; what does, however, is if funding is available for an adequate number of staff, tutorials, and an efficient IT infrastructure. And they receive a poorer education if these funds are not available.

Surprisingly, accreditation seems to have a higher impact outside academia than within. Practitioners, employers and prospective students are asking for accreditation. Apparently, it is politics and the public opinion (or opinion leaders) which have managed to provide the accreditation system with a positive image. Thus, some benefits of accreditation can be assumed since an accredited course of study initially is considered to be better than a nonaccredited one. However, which of the many accreditation agencies has awarded the accreditation seems to be secondary.

Only upon closer examination can we see the disadvantages incurred by the overheads of accreditation. The universities are deprived of many millions of Euros which are no longer available for the actual tasks of education. Moreover, also the study programs themselves suffer from having to fulfill rigid formal requirements. Even the amount of time to be spent by the students for their studies is standardized in ECTS numbers and hour-equivalent figures. A bachelor's degree has to include 30 ECTS points (= 900 hours) per semester, not 31 and not 29. If a curriculum e. g. makes up 29 points based on professional aspects, the program does not meet the accreditation requirements. If 31 ECTS (= 930 hours) are the result, the program is considered to be "non-studyable"; i. e. it is more than students can cope with!

Even the WKWI pointed to the impact of these relatively low requirements for the international competitiveness of our graduates in its recommendations for education: "Given the special conditions of an interdisciplinary field and the high demands made by good universities on students of comparable subjects in the international area, it is desirable to significantly increase the low values allowed for the sum of working hours of a student (1800 per year) in Germany. This may lead to the conveyance of competitive knowledge beyond Europe." (Fachkommission Wirtschaftsinformatik 2007, p. 324)

A note in passing: The burden which accompanies accreditation at least partially has innovation-impeding effects. Recently I discussed the idea of an innovative new study program with my colleagues once again. While the idea itself filled us with enthusiasm, nobody agreed to actually take charge of the plan. The accreditation effort had a deterrent effect.

Prof. Dr. Karl Kurbel Chair of Business Informatics Europe University Viadrina Frankfurt/Oder

\section{References}

Fachkommission Wirtschaftsinformatik (2007) Rahmenempfehlung für die Universitätsausbildung in Wirtschaftsinformatik. WIRTSCHAFTSINFORMATIK 49(4):318-326 


\section{Strengthening Competitiveness on the Way Towards Bologna}

The FIBAA (Foundation for International Business Administration Accreditation) carries out program and institutional (system) accreditations with the help of mostly international reviewer teams. Apart from the German-speaking countries (Germany, Liechtenstein, Austria, Switzerland), the FIBAA operates in more than a dozen other states as an international accreditation agency. The FIBAA is officially approved in Germany, Switzerland, and the Netherlands, and is one of the nine accreditation agencies which have been included in the European Quality Assurance Register; moreover, the agency is a member of numerous international quality assurance networks.

The focus of the accreditation activity is currently set on study programs in business administration. In Germany, the FIBAA is market leader with more than $60 \%$ of accredited programs in the field of business administration. In BISE, the FIBAA accredited a total of 35 study programs at 24 universities during the last 5 years (2004-2008), including 25 bachelor's degrees.

On the background of this experience the following observations can be noted as an answer to the question: "Accreditation of BISE: Towards more competitiveness or towards more bureaucracy?":

1. Accredited study programs have a signal effect especially for prospective students. According to student interviews during the accreditation process, the fact that a course is accredited has significant influence on their decision. Accreditation is also important for the universities with regard to competitiveness. In contrast, accreditation of a study program still seems to be of lesser importance for the employers. Thus, the signal effect of accreditations for the involved groups varies in intensity.

2. Program accreditation is about demonstrating the quality of the study program. As an international agency the FIBAA follows the European Standard and Guidelines (ESG), which apply to quality assurance in the study programs of the Bologna states, as well as the requirements of the German accreditation council. It has been shown that the universities often have difficulties with the paradigm shift from the hith- erto prevailing input orientation to the learning outcome orientation of the Bologna process. The understanding of what is meant by modularization often is still underdeveloped. This not only leads to deficiencies in the description of each module's learning objectives, but in consequence to deficiencies in demands concerning the contents of performance tests, which must follow the integrative approach of the module. The trend towards partial credits for the purposes of course exams is mostly still continuing; the integrative approach of a module exam, as necessary within modularization, is often not achieved.

- Whoever sees these - internationally valid - requirements as a proof for a stronger bureaucratization caused by the accreditation demanded in Germany, has not (yet) understood the Bologna process. Both the modularization of the program and the alignment of exams to the skills and competencies which have to be proved as achieved exclusively serve - and this is different to before - the imparting and proof of professional competence of graduates, which ultimately is the goal of their studies.

3. The decision for an agency should to a large extent be determined by the agency's reputation in its field of activities. According to competitive aspects it is also important whether the agency mainly operates nationally or internationally. Due to its international reputation, the FIBAA is a popular agency not only for study programs in business administration in the strict sense, but also for BISE, business psychology, business law, and other hybrid study programs.

4. Since the agencies operating in Germany all have to meet the requirements of the German accreditation council, compliance with all minimum requirements can be ensured. However, there are differences in the procedures. The FIBAA is probably the only agency that makes the quality criteria and benchmarks transparent for the universities and mandatory for the reviewers. Thus, the university knows at an early stage what is important for a successful accreditation. In addition, the uniformity of assessments through different groups of reviewers is effectively supported.
5. One of the experiences of re-accreditation is that the know-how available at the time of the initial accreditation is no longer available due to staff changes. Therefore a kind of job profile for quality managers, program managers, or study program managers would certainly be worth considering. However, past experiences also show that a separation between scientific management and program management does not always lead to the desired result.

6. The freedom of research and teaching is not affected by the modularization of a study program and the conversion from lecturer-oriented teaching to student-centered mediation is not affected, much less is it questioned. Both with regard to content and methods the lecturer remains free. However, the learning objectives, i. e. the qualifications and skills that have to be imparted, are not accessible to individual disposition by the lecturer considering the desired qualifications of graduates.

In conclusion: on the whole, external quality assessment in the form of program accreditations has proved to be of value because it subserves continuous quality improvement as well as quality assurance. The quality profile, which is compiled by the FIBAA during the assessment for each course of study, clearly identifies the program's strengths and weaknesses. For program managers and the relevant committees at universities, this highlights where development potential exists. Thus, accreditation has proved to be an element of strengthening a university's competitiveness.

Dr. Heinz-Ulrich Schmidt Foundation for International Business Administration Accreditation (FIBAA)

\section{Accreditation as an Internal and External Quality Signal}

From a reviewer's perspective, the study program which is to be accredited appears at a snapshot presenting a positive selection of documents and individuals. Internal discussions, the creation process of documents, possible tensions between the participating professors, the university management, and other involved parties are possibly hidden from the reviewers. At the time of accreditation internal opponents of the presentation's content or 
of the accreditation process usually do not appear; instead the people interviewed, whether they are lecturers or students, mainly send positive quality signals as supporters of the process.

However, the addressees of this performance not only consist of the external reviewers of the accreditation agency, who are supposed to accept the presented contents, the focus, and the objectives of the study program in a "peer review" directly or with minor suggestions for improvement. The agreement of the external reviewers itself is only a signal which is sent to three other groups of recipients:

1. The internal opponents, i. e. other professors of one's own department or university who are to be convinced by justifying the accreditation;

2. The university management, considering accreditation to be a bureaucratic process which has to be managed efficiently;

3. Current and prospective students and their future employers, who are supposed to trust this program or the university in an uncertain world of education.

Behind accreditation therefore is a longterm internal discussion process which begins far ahead of the ultimate accreditation, the consequences of which continue to have impacts still for a long time afterwards. During the process, supporters and opponents discuss the unique features of the study program, its focus, objectives, and finally the contents to be emphasized in the accreditation. The accreditation or the presence of the reviewers only is the trigger, a singular event, which helps to clarify one's own position. The continuing existence of this discussion process and the appointment of responsible persons (study program facilitators) in the department (not in the management!) is the main result of an accreditation. In this discussion process, the reviewers can only give impetus for change concerning all the three beneficiary groups, but that is all.

Ad 1: Professors, who often withdraw from the internal discussion with the argument that the "freedom of research and teaching" prohibits the attempt to focus on a study program at all, are the hardest to convince. Focusing a study program also means to review old habits and abolish them if necessary. While the motivation of the reviewers of an accreditation, as in "peer review" of scientific articles, usually derives from the curiosity for something different and the application of their own expertise to improve what is there, this requires openness, listening to expertise, and possibly adopting it on part of the university to be accredited. On the part of the accreditation agencies this requires that the reviewers who carry out the assessment and assert recommendations are in fact positioned as "peers". Unfortunately, the incentive situation for reviewers in Germany currently cannot ensure a level of quality corresponding to a scientific "peer review". This regrettably shows that accreditation is not taken as seriously as would be useful in view of its signal effect.

Ad 2: Within the university management, we have to introduce a quality management process which implements a professional and efficient handling of the management of recurring accreditation for all courses of study (up to several hundred depending on the university). Friction will evolve where in a concrete accreditation situation the forms and processes of a standardized quality management collide with a desire to document the position and creativity of the program. In this situation, the reviewers are called on focusing the positive unique features and unique advantages of the program. The reviewer must not give in to the temptation of wanting to enforce a way of standardization using normalized curricula (which the management willingly accepts), but should strengthen existing competitive advantages and openly respond to disadvantages, thus acting more like a strategy consultant. This in turn requires appropriate skills on the reviewers' side and their respective selection by the accreditation agency.

Ad 3: As long as content, focus, and direction of the study program remain unassigned within the university, accreditation may help to reveal internal conflicts and stimulate a discussion, which has to go beyond the period of accreditation. Each accreditation agency which is internally taken seriously or its reviewer(s) fulfill this purpose for low fees, if you take into account the internal quality signal, the group discussion at the university, and the documentation of a program's focused strategy as the main result.

Once the focus is set, the external signal direction gains importance for future candidates and their employers for winning the competition themselves. The selected accreditation agency is supposed to cre- ate trust in the program and make it comparable with other accredited programs, especially in areas where the qualitative amount of comparative courses is relatively high. If the label "university", "bachelor" or "master" do not permit a conclusion about the quality of the program as there are (too) many of them, the accreditation signal has to take their position.

Only in the case of Executive MBA study programs, which aim at recruiting as many paying students as possible by means of the external quality signal, there is a real cost-benefit calculus. In this case, and since most internationally oriented accreditation agencies accredit the "school" and not the study program, all other programs benefit apart from these EMBA courses. In a similar way as in researcher or university rankings, institutions sending the same accreditation signals appear comparable. Those who can afford it therefore choose a comparatively expensive accreditation agency with wellknown clients in terms of separation equilibrium.

In conclusion: universities aiming at accreditation should first be aware of their position within the internal discussion process and whether the internal or external signal effect should predominate. For the internal signal effect and for stimulating the discussion process the quality of the reviewers should be the crucial criterion; if they are not their "peers", the quality of the accreditation result will not be satisfactory. For the external signal effect, however, national and international competition alone count as a benchmark.

Prof. Dr. Torsten Eymann Chair of Information Systems Management University of Bayreuth 